\title{
Machinability Evaluation in Hard Milling of AISI D2 Steel
}

\author{
Vinayak Neelakanth Gaitonde ${ }^{a *}$, Sulse Ramesh Karnik ${ }^{b}$, Caio Henrique Alves Maciel', \\ Juan Carlos Campos Rubio ${ }^{c}$, Alexandre Mendes Abrão
}

\author{
${ }^{a}$ Department of Industrial and Production Engineering, B. V. B. College of Engineering and \\ Technology - BVBCET, Hubli-580 031, Karnataka, India \\ ${ }^{b}$ Department of Electrical and Electronics Engineering, B. V. B. College of Engineering and \\ Technology - BVBCET, Hubli-580 031, Karnataka, India \\ 'Department of Mechanical Engineering, Laboratory of Machining and Automation,
} Universidade Federal de Minas Gerais - UFMG, Av. Antônio Carlos 6627, Belo Horizonte, MG, Brazil

Received: May 13, 2015; Revised: September 28, 2015; Accepted: December 22, 2015

\begin{abstract}
Milling of hardened steel components provides considerable benefits in terms of reduced manufacturing cost and time compared to traditional machining. Temperature variation in milling is an important factor affecting the wear of cutting tools. The poor selection of milling parameters may cause excessive tool wear and increased work surface roughness. Hence, there is a need to study the machinability aspects during milling of hardened steel components. In the present work, influence of cutting speed, feed rate and radial depth of cut on milling temperature, surface roughness and cutting force during milling of AISI D2 steel has been investigated using response surface methodology (RSM) based models. From the parametric analysis, it is revealed that temperature increases linearly, whereas surface roughness increases non-linearly with cutting speed. However, for higher values of feed rate, an increased cutting speed considerably reduces the cutting force for specified depth of cut range. The present work also reveals that the selection of best cutting conditions is useful at the CAPP stage in the milling process particularly with tight tolerances.
\end{abstract}

Keywords: AISI D2 steel, hard milling, cutting force, surface integrity, temperature.

\section{Introduction}

The amount of material removed during machining is generally related to the manufacture cost. Varying parameters such as cutting speed and/or feed rate can make the process more cost effective; however, there are some limitations owing to the fact that tool life decreases with the elevation of cutting. Studies related to the proper selection of the parameters and monitoring of machining forces based on the temperature can be conducted with the goal of maximizing the material removal rate. Similarly, the analysis of cutting forces allows an overview of the machining process in order to evaluate the level of tool wear and resulting surface finish ${ }^{1}$.

Milling of hardened steel components provides substantial benefits in terms of reduced manufacturing cost and production time when compared to traditional route consisting of machining in the annealed condition, heat treatment, electrical discharge machining, grinding and manual polishing ${ }^{2,3}$. A large number of studies related to the machining of hardness steels mainlydeals with the manufacture a wide range of molds and dies. Wang et al., ${ }^{4}$ performed experimental studies on high-speed milling (HSM) of SKD11/HRC 62 and S136/HRC 51 hardened steels using TiAIN and TiSiN PVD-coated carbide tools to determine the mechanism of cutting tool wear and breakage. The influence of tool angle, tool diameter, tool extended length, cutting force and cutting-induced vibration on the

*e-mail: gaitondevn@yahoo.co.in tools has been studied. Cutter with a small rake angle, appropriate clearance angle and large helix angle found to be beneficial for reducing the cutting force as well as tool wear. Further, Chengyong et al., ${ }^{5}$ carried out an extensive research on chip formation mechanism during high speed milling of hardened steels. An investigative study on tool wear mechanism and surface integrity in high speed end milling of hardened AISI A2 tool steel using coated tungsten carbide and polycrystalline cubic boron nitride (PCBN) tools was performed by $\mathrm{Pu}, \mathrm{Singh}^{6}$. Their investigation revealed that the carbide tool is suitable for low speed, while the PCBN tool is appropriate for selected high speed machining range.

A comparative study on tool life of sintered carbide (TiAlN coating) with cubic boron nitride ball end mills on hardened steel X155CrVMo12-1 was presented by Wojciechowski, Twardowski ${ }^{7}$. Wojciechowski, Twardowski ${ }^{8}$ also carried out further research on the analysis of tool's vibrations generated during ball end milling process of above work materials. The milling experiments on hardened AISI H13 steel were performed by de Aguiar et al., ${ }^{9}$ using integral and indexable insert tools with different tool overhangs and different diameters. Tool wear, workpiece surface roughness and cutting forces were analyzed. Liao, Lin ${ }^{10}$ reported that the tool life can be successfully enhanced using MQL application in HSM of NAK80 hardened steels by selecting the proper cutting parameters. A feasibility study on the 
minimum quantity lubrication (MQL) in high-speed end milling of NAK 80 hardened steel by coated carbide tool was undertaken by Liao et al. ${ }^{11}$. MQL application improved surface finish in high-speed milling of die steels and also could delay welding of chips on the tool and hence prolongs tool life when compared to dry machining.

Experimental study on the high speed machining of hardened steel was performed by Begic-Hajdarevic et al. ${ }^{12}$ The results indicated that the better surface quality could be achieved in high speed machining of examined steel but at the cost of rapid tool wear. The experimental studies were carried out by Durakbasa et al., ${ }^{13}$ on the optimization of end milling parameters and the determination of the effects of edge profile for high surface quality of AISI H13steel using precise and fast measurements. The wear performance of end mill tools with different PVD coatings has been studied under the condition of hard wet machining of H13 tool steel by Beake et al. ${ }^{14}$. The use of nanoindentation, nano-impact and micro-scratch testing to predict the wear behaviour of studied coated tools was discussed in their studies. The experimental and theoretical studies on the workpiece temperature during end milling of AISI H13 and AISI D2 hardened steels using (TiAl)N-coated and PCBN-tipped tools were performed by Brandão et al. ${ }^{15}$ The experimental investigations on hard milling of high strength steel 30Cr3SiNiMoVA (30Cr3) using PVD-AlTiN coated cemented carbide tool was performed by Qinglong A et al. ${ }^{16}$ It was observed that the occurrence of oxidation on chip surfaces under high cutting temperature makes the chips show different colors which are strongly influenced by cutting speed. The cutting performance of the coated end mills was observed in high-speed dry milling hardened steel (P20, HRC 45) by Lu et al. ${ }^{17}$ The coated end mills demonstrate noteworthy enhancement on tool life and a large amount lower cutting force as compared to the uncoated ones.

It is seen that, information regarding the machining of AlSI D2 grade tool steels is scarce despite their ample use in rolling operations ${ }^{18}$. Koshy et al., ${ }^{18}$ conducted tool life tests during milling of AISI D2 steel using various grades of coated carbide tools. The results suggest that the lower tool life observed at the lowest feed rate $(0.05 \mathrm{~mm} /$ tooth $)$ can be attributed to inefficient removal of material (resulting from insufficient undeformed chip thickness) in contrast to more efficient cutting when a larger feed rate $(0.1 \mathrm{~mm} /$ tooth $)$ is used. Furthermore, they showed that tool life decreases with the elevation of cutting speed. The machinability of tools steel can be improved by changing their chemical composition or preliminary heat treatment. In the case of AISI D2 tool steel, its machinability is approximately $30-40 \%$ of AISI B 1112 free cutting steel ${ }^{19}$. Using FEM simulation, Seadon et al., ${ }^{2}$ asserted that tool life criterion is one of the main aspects used to evaluate the performance of cutting tools in material removal operations. The authors used the analysis of variance and concluded that cutting speed is the predominant factor followed by feed rate and depth of cut. Iyer et al., ${ }^{3}$ showed that the maximum Von Mises stress reached during machining of AISI D2 steel is practically twice that of AISI H13 steel under the same machining conditions. Furthermore, the authors predicted the temperature values of approximately $700 \mathrm{~K}$ when machining hardened steel at a cutting speed of $20 \mathrm{~m} / \mathrm{min}$ and considering a friction coefficient of 0.3. Nurul Amin et al., ${ }^{20}$ ascertained the usefulness of brazed circular polycrystalline cubic boron nitride (PCBN) inserts in end milling of AISI D2 steel under room temperature and workpiece preheated conditions. A systematic comparative analysis in terms of chatter intensity, chip formation instability, tool wear and metal removal capacity of the tool and surface roughness of the milled components was performed.

The development of new types of coatings has allowed an improvement in the mechanical and chemical properties of tungsten carbide tools, thus leading to increased lifetime and allowing not only increased production rate, but also decrease in consumption or elimination of cutting fluids ${ }^{21}$. The investigation conducted by Kang et al., ${ }^{21}$ on milling of AISI D2 tool steel also revealed that coated tools present superior performance in dry machining. They reported that under flooding, the cooling action causes severe tool wear by thermal fatigue wear thus resulting in increased tool wear rate compared with dry cutting or using minimal quantity lubrication (MQL). Okada et al., ${ }^{22}$ compared the temperature for two tool materials, namely cubic boron nitride (CBN) and coated cemented tungsten carbide during milling of AISI D2 steel and lower temperatures were recorded when milling with $\mathrm{CBN}$ due to its higher thermal conductivity. Nurul Amin et al., ${ }^{20}$ showed that preheating the workpiece above $150^{\circ} \mathrm{C}$ promotes lower levels of vibration and roughness during machining, thus improving the machinability of A1SI D2 steel. With regard to tool wear, preheating the workpiece caused higher initial wear; however, an exponential increase in wear was observed when the workpiece was machined at room temperature.

As can be seen from the literature, only few works have been carried in milling of harder materials. Further, no methodological study has been reported on machinability behavior of hard milling. Hence, the present investigation evaluates some aspects of milling of hardened AISI D2 tool steel using end mill cutters with TiAlN coated tungsten carbide inserts. The influence of cutting speed, feed rate and radial depth of cut on various aspects of machinability such as temperature, surface roughness and cutting force has been performed by constructing the quadratic models based on response surface methodology (RSM). The mathematical modeling based on RSM using design of experiments (DOE) is proved to be an efficient modeling tool ${ }^{23}$. The RSM provides the necessary information concerning the main and interaction effects of process parameters with a minimum number of experiments.

\section{Methodology}

The response surface methodology (RSM) is a widespread modeling tool applied for ascertaining the relationship(s) between the factors and the desired characteristic(s). The RSM is helpful for developing, analyzing, improving and optimizing a product/process ${ }^{23}$. The modeling of preferred characteristics to different factors can be acquired through design of experiments (DOE) and applying the regression technique. The DOE is practical in studying the direct and interaction effects of process parameters with reduced experiments. In a number of circumstances, it is proficient 
to represent the process parameters in quantitative form and the desired characteristic can be expressed as ${ }^{23}$ :

$$
Y=\varphi\left(x_{1}, x_{2}, x_{3}, \ldots \ldots . . x_{k}\right)
$$

where $Y$ is the characteristic or response, $x_{1}, x_{2}, x_{3}, \ldots \ldots . . . x_{k}$ are the input factors or parameters and $\varphi$ is the response function. Furthermore, Equation (1) can be approximated within the experimental region by a polynomial when the mathematical form of response function is unfamiliar.

\section{Experimental procedure}

Experimental plan is crucial to construct the models using RSM. Modeling offers the equations attained through the data of planned experiments through DOE. In the current work, cutting speed $(v)$, feed rate $(f)$ and radial depth of cut $(d)$ are identified as the parameters; evaluated through

Table 1: Process parameters and their levels

\begin{tabular}{lccc}
\hline \multirow{2}{*}{ Parameter } & \multicolumn{3}{c}{ Level } \\
\cline { 2 - 4 } & $\mathbf{1}$ & $\mathbf{2}$ & $\mathbf{3}$ \\
\hline Cutting speed $(v), \mathrm{m} / \mathrm{min}$ & 90 & 135 & 180 \\
Feed rate $(f), \mathrm{mm} / \mathrm{rot}$ & 0.1 & 0.2 & 0.4 \\
Depth of cut $(d), \mathrm{mm}$ & 4 & 8 & 12 \\
\hline
\end{tabular}

three characteristics, namely maximum milling temperature $\left(T_{\max }\right)$, work surface roughness $\left(R_{a}\right)$ and cutting force $\left(F_{c}\right)$. The range of the parameters was selected based on preliminary experiments and three levels were selected for individual parameter. The importance of process parameters was studied through a set of experiments based on a full factorial design (FFD) to examine the quadratic response surface ${ }^{23}$; thus, 27 trials were performed. The parameters and their levels are presented in Table 1 and the experimental plan is given in Table 2.

AISI D2 tool steel was used as work material for the current experimentation. Tool steel (grade D) materials are largely used in the manufacture of cold forming dies owing to excellent wear characteristics and deep hardening. Commonly grade $\mathrm{D}$ steels are provided in the annealed condition with maximum hardness of $255 \mathrm{HB}$. The chemical composition of AISI D2 steel is given in Table 3. Kang et al., ${ }^{21}$ recommended carbide tools for improved performance in dry milling of AISI D2 tool steel. Hence, coated tungsten carbide inserts (code '390-11 T3 13E-PM 1010') were mounted on an end mill cutter (code 'K390-016A16L-116'); both manufactured by Sandvik Coromant and used throughout the investigation. Unlubricated milling experiments were performed on a machining center (ROMI Discovery 560) that is equipped with $9 \mathrm{~kW}$ spindle power and a maximum spindle speed of $7500 \mathrm{rpm}$.

Table 2: Experimental layout plan and the measured values of temperature, surface roughness and cutting force

\begin{tabular}{|c|c|c|c|c|c|c|}
\hline \multirow{2}{*}{ Trial No. } & \multicolumn{3}{|c|}{ Actual parameters settings } & \multicolumn{3}{|c|}{ Response* } \\
\hline & $v(\mathrm{~m} / \mathrm{min})$ & $f(\mathrm{~mm} / \mathrm{rot})$ & $d(\mathrm{~mm})$ & $T_{\max }\left({ }^{\circ} \mathrm{C}\right)$ & $R_{a}(\mu \mathrm{m})$ & $F_{c}(\mathbf{N})$ \\
\hline 1 & 90 & 0.1 & 4 & 381.99 & 0.50 & 57.97 \\
\hline 2 & 90 & 0.2 & 4 & 383.33 & 0.46 & 56.32 \\
\hline 3 & 90 & 0.4 & 4 & 384.60 & 0.80 & 186.38 \\
\hline 4 & 135 & 0.1 & 4 & 396.58 & 0.44 & 50.36 \\
\hline 5 & 135 & 0.2 & 4 & 398.97 & 0.35 & 54.68 \\
\hline 6 & 135 & 0.4 & 4 & 406.85 & 0.47 & 110.08 \\
\hline 7 & 180 & 0.1 & 4 & 424.61 & 0.29 & 42.90 \\
\hline 8 & 180 & 0.2 & 4 & 415.34 & 0.37 & 74.60 \\
\hline 9 & 180 & 0.4 & 4 & 430.95 & 0.28 & 120.83 \\
\hline 10 & 90 & 0.1 & 8 & 406.80 & 0.40 & 83.68 \\
\hline 11 & 90 & 0.2 & 8 & 400.24 & 0.60 & 74.21 \\
\hline 12 & 90 & 0.4 & 8 & 444.30 & 1.05 & 247.77 \\
\hline 13 & 135 & 0.1 & 8 & 430.32 & 0.49 & 71.91 \\
\hline 14 & 135 & 0.2 & 8 & 422.67 & 0.71 & 92.64 \\
\hline 15 & 135 & 0.4 & 8 & 454.10 & 0.95 & 246.55 \\
\hline 16 & 180 & 0.1 & 8 & 458.02 & 0.50 & 82.21 \\
\hline 17 & 180 & 0.2 & 8 & 448.63 & 0.76 & 126.13 \\
\hline 18 & 180 & 0.4 & 8 & 464.40 & 1.21 & 190.83 \\
\hline 19 & 90 & 0.1 & 12 & 421.61 & 1.10 & 185.95 \\
\hline 20 & 90 & 0.2 & 12 & 409.64 & 1.02 & 218.99 \\
\hline 21 & 90 & 0.4 & 12 & 430.40 & 1.72 & 536.3 \\
\hline 22 & 135 & 0.1 & 12 & 472.14 & 0.58 & 134.44 \\
\hline 23 & 135 & 0.2 & 12 & 456.44 & 0.76 & 233.48 \\
\hline 24 & 135 & 0.4 & 12 & 459.25 & 1.16 & 397.76 \\
\hline 25 & 180 & 0.1 & 12 & 495.78 & 0.54 & 153.92 \\
\hline 26 & 180 & 0.2 & 12 & 487.68 & 0.93 & 245.68 \\
\hline 27 & 180 & 0.4 & 12 & 466.98 & 1.67 & 366.36 \\
\hline
\end{tabular}


Temperature acquisition was performed with a 'Raytek $M M^{\prime}$ ' infrared camera (focal diameter of $1.9 \mathrm{~mm}$, focal distance of $300 \mathrm{~mm}$ and operating range from 300 to $1100^{\circ} \mathrm{C}$ ) mounted on a tripod. The temperatures measured with the infrared camera were acquired with the aid of a computer and software 'Data Temp Multidrop 5.3.1'. The acquisition system was set in order to record the maximum value measured in each second.

By means of the communication adapter that connects the machining center to the computer, the values of electric current consumed by the main spindle motor were recorded. In order to obtain the cutting forces, electric current was initially measured with the spindle running idle for the three cutting speeds tested. The difference between the electric current during cutting and idle $(\Delta \mathrm{I})$ can be used to estimate the cutting force.

For the measurement of machined surface roughness after each pass, the specimen was previously marked to determine its beginning (left half) and end (right half). Each test was performed twice with three measurements of surface roughness at beginning, middle and end of the machined surface and the average value was used to plot

Table 3: Chemical composition of AISI D2 tool steel work material (wt \%)

\begin{tabular}{cccccc}
\hline $\mathbf{C}$ & $\mathbf{S i}$ & $\mathbf{M n}$ & $\mathbf{C r}$ & Mo & $\mathbf{V}$ \\
\hline 1.55 & 0.30 & 0.40 & 11.80 & 0.80 & 0.80 \\
\hline
\end{tabular}

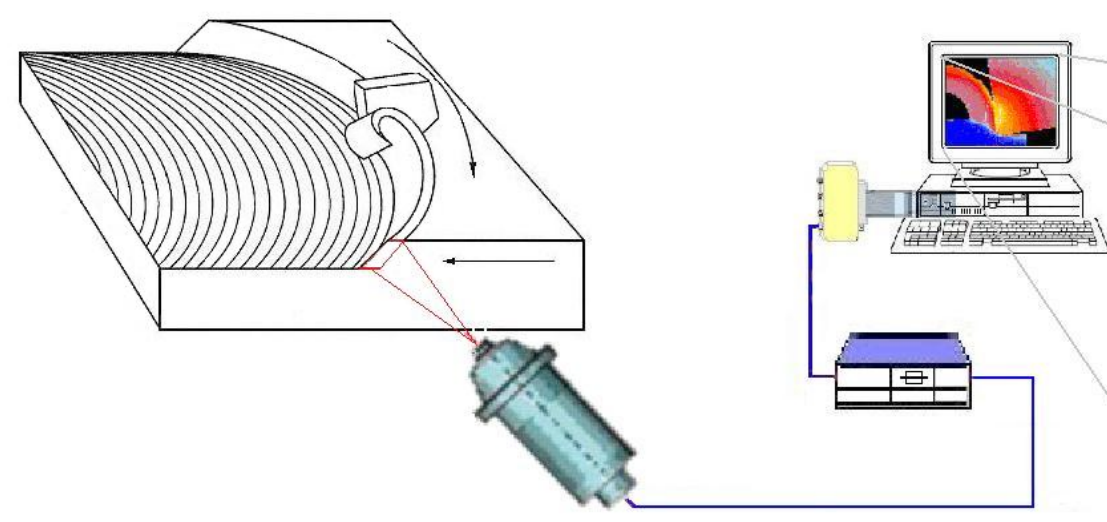

the graphs. The roughness parameter was measured using a 'Taylor Hobson Surtronic 25' Roughness Tester with a cut-off of $0.8 \mathrm{~mm}$.

The measured values of maximum milling temperature $\left(T_{\max }\right)$, surface roughness of workpiece $\left(R_{a}\right)$ and cutting force $\left(F_{c}\right)$ are summarized in Table 2 . The photographs of experimental setup for measuring temperature and surface roughness during milling and an aspect of hard milling are illustrated in Figures 1-3 respectively.

\section{Results and discussion}

\subsection{Mathematical modeling}

In the current study, the quadratic models based on RSM for milling temperature $\left(T_{\max }\right)$, surface roughness $\left(R_{a}\right)$ and cutting force $\left(F_{c}\right)$ have been developed with cutting speed $(v)$, feed rate $(f)$ and radial depth of cut $(d)$ as the input parameters. The second order mathematical model considering two parameter interactions is given by ${ }^{23}$ :

$Z=c_{0}+c_{1} v+c_{2} f+c_{3} d+c_{4} v^{2}+c_{5} f^{2}+c_{6} d^{2}+c_{7} v f+c_{8} v d+c_{9} f d$

where, $\mathrm{Z}$ is the desired criterion and $c_{0}, c_{1} \ldots c_{9}$ are the regression coefficients of the quadratic model to be determined for each criterion. The regression coefficients of Equation (2) are determined by ${ }^{23}$ :

$C=\left(X^{T} X\right)^{-1} X^{T} Z$

Figure 1. Experimental setup for measuring milling temperature
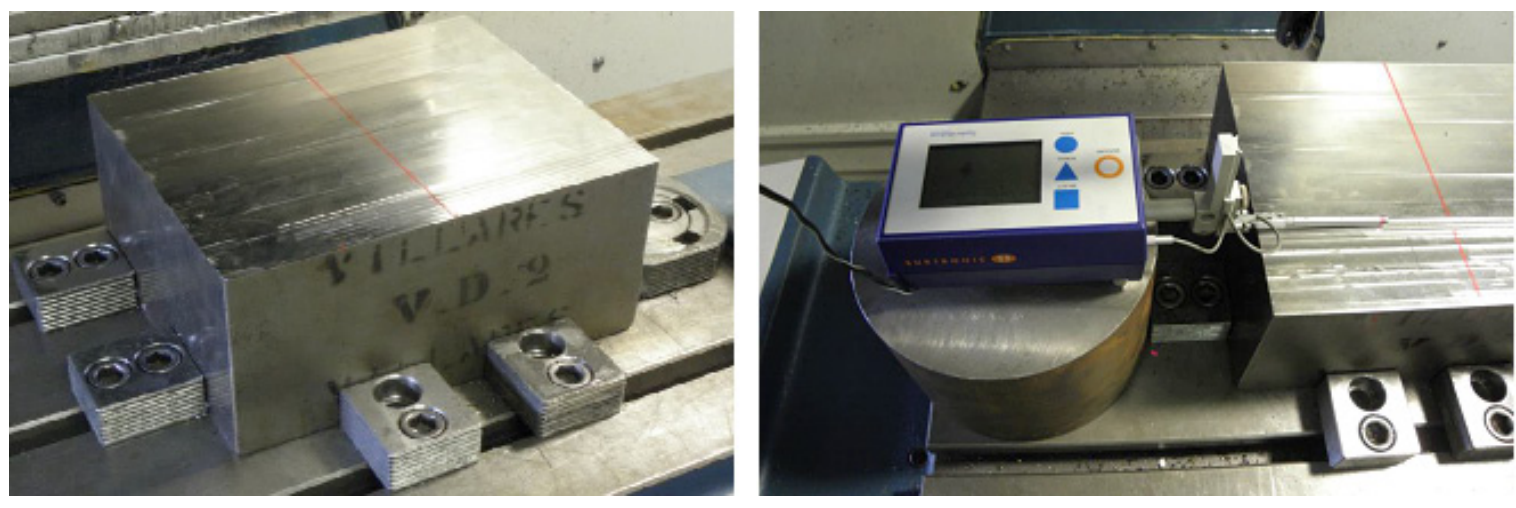

Figure 2. Clamping the workpiece to be machined and measuring surface roughness 
where, $C$ is the matrix of factor estimates, $X$ is the calculation matrix, which includes linear, quadratic and interaction ; $X^{T}$ is the transpose of $X$ and $Z$ is the matrix of desired criterion. The regression coefficients of the quadratic models for temperature $\left(T_{\max }\right)$, surface roughness $\left(R_{a}\right)$ and cutting force $\left(F_{c}\right)$ during milling of AISI D2 steel using TiAlN coated tungsten carbide insert are obtained through Equation (3) and are given by:

$T_{\max }=275.3247222+0.76512963 v-42.8265873 f+$ $11.52805556 d-0.001079287 v^{2}+460.57407 f^{2}-$

$0.4716 d^{2}-0.83421 v f+0.031394 v d-6.85625 f d$

$R_{a}=1.787314815-0.019833333 v-1.868650794 f-$

$0.002430556 d+0.0000652949 v^{2}+2.0555556 f^{2}+$

$0.000347 d^{2}+0.00172 v f+0.0000556 v d+0.283035714 f d$
$F_{c}=178.8244444-1.020111111 v-118.9611111 f-$

$31.37444444 d+0.007331413 v^{2}+1109.9074 f^{2}+$

$2.760903 d^{2}-3.61048 v f-0.05229 v d+77.70178571 f d$

where, $v$ in $\mathrm{m} / \mathrm{min} ; f$ in $\mathrm{mm} / \mathrm{rot} ; d$ in $\mathrm{mm} ; T_{\max }$ in ${ }^{\circ} \mathrm{C}, R_{a}$ in $\mu \mathrm{m} ; F_{c}$ in N.

The competence of the developed quadratic models (Equations 4-6) has been tested through the analysis of variance (ANOVA) ${ }^{23}$. As specified by the ANOVA, the computed value for F-ratio of the developed mathematical model should be more than F-ratio of Fisher table for the model to be satisfactory for a particular confidence interval. The ANOVA results are given in Table 4, which undoubtedly reveals that the developed models are significant at $99 \%$ confidence interval. The adequacy of fit of the RSM based models was also tested through the coefficient of correlation $\left(R^{2}\right)$, which is the variation in the criterion explained by quadratic model. The $R^{2}$ values of the developed models

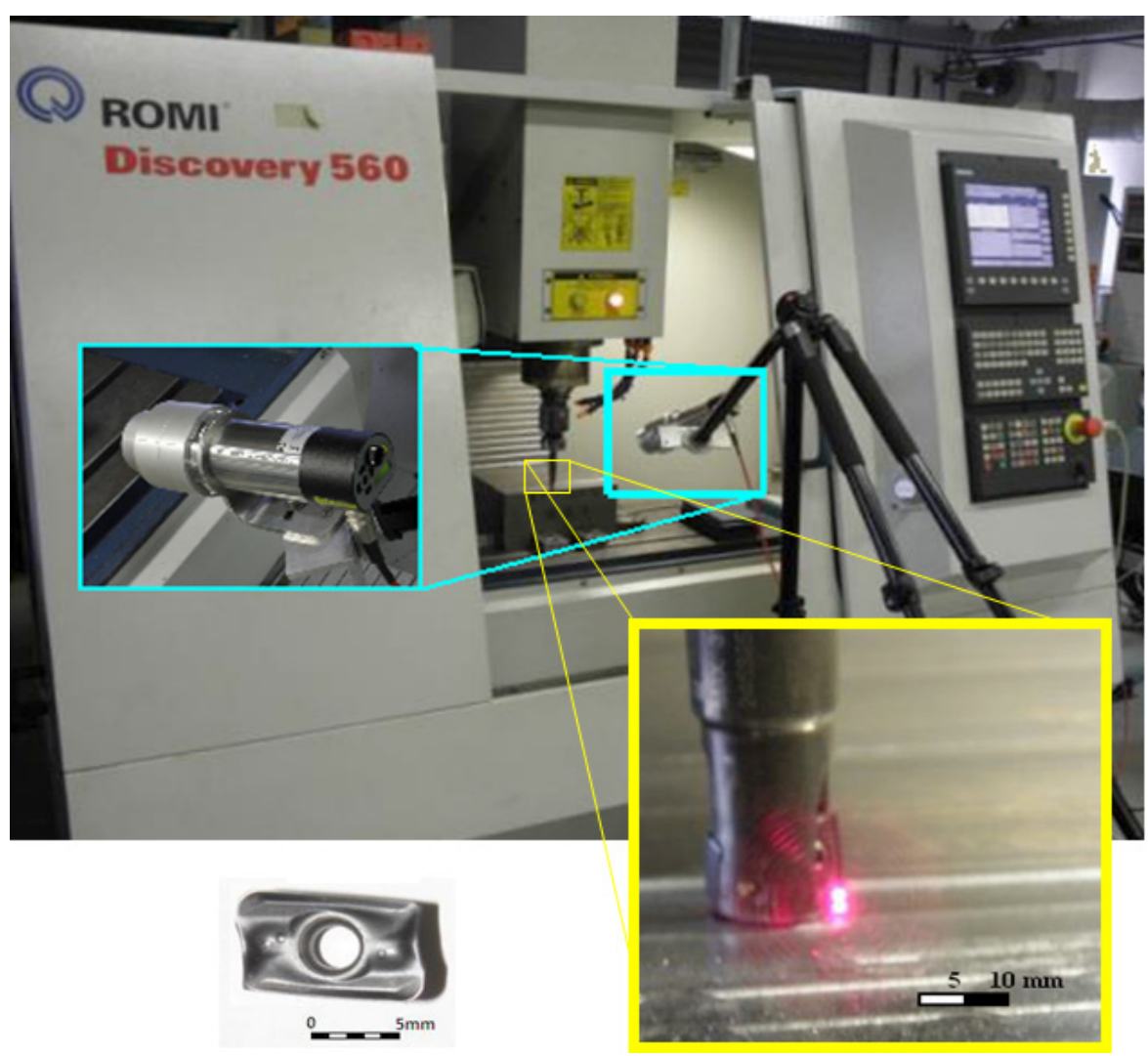

Figure 3. Experimental set-up, Raytek Infrared Camera and end mill cutter with TiAlN coated tungsten carbide inserts

Table 4: Summary of ANOVA and $\mathrm{R}^{2}$ values of machinability models

\begin{tabular}{|c|c|c|c|c|c|c|c|c|}
\hline \multirow{2}{*}{ Machinability } & \multicolumn{2}{|c|}{ Sum of squares } & \multicolumn{2}{|c|}{ Degrees of freedom } & \multicolumn{2}{|c|}{ Mean square } & \multirow{2}{*}{ F-ratio } & \multirow{2}{*}{$R^{2}$} \\
\hline & Regression & Residual & Regression & Residual & Regression & Residual & & \\
\hline Temperature $\left(T_{\max }\right)$ & 25018.1 & 1735 & 9 & 17 & 2779.8 & 102.1 & 27.24 & 0.9351 \\
\hline Surface roughness $\left(R_{a}\right)$ & 3.42901 & 0.50546 & 9 & 17 & 0.3810 & 0.02973 & 12.81 & 0.8715 \\
\hline Cutting force $\left(F_{c}\right)$ & 363063 & 13503 & 9 & 17 & 40340 & 794 & 50.79 & 0.9641 \\
\hline
\end{tabular}

F- table ${ }_{(9,17,0.01)}=3.68$ 
(Table 4) also point out better correlation between experimental and predicted values of proposed criteria. The assessment of the experimental and the predicted values of $T_{\max }, R_{a}$ and $F_{c}$ for the experimental data of FFD during milling of AISI D2 tool steel with TiAIN coated tungsten carbide insert is illustrated in Figures 4-6 respectively. For the validation purpose, the new experiments were conducted consisting of combinations of process parameters which do not belong to the experimental data. It is seen from Table 5 that the experimental and the predicted values of proposed RSM based quadratic models agree with each other.The proposed quadratic models (Equations 4-6) were used to predict the maximum temperature $\left(T_{\max }\right)$, surface roughness $\left(R_{a}\right)$ and cutting force $\left(F_{c}\right)$ by substituting the values of cutting speed $(v)$, feed rate $(f)$ and radial depth of cut $(d)$ within the ranges of the parameters selected. The effects of the process parameters on temperature $\left(T_{\max }\right)$, surface roughness $\left(R_{a}\right)$ and cutting force $\left(F_{c}\right)$ during milling of AISI D2 tool steel were analyzed (Figures 7, 9 and 10). The proposed machinability characteristics were plotted as a function of cutting speed with hold values of three different combinations of feed rate and depth of cut.

\subsection{Analysis of temperature}

In machining, the workpiece, cutting tool and chip warm up in the cutting zone. The mechanical energy is converted into thermal energy owing to plastic strain and friction between of the chip and the rake and clearance surfaces of the cutting tool and hence temperature increases. Figure 7 illustrates the variation of maximum temperature as a function of cutting speed with three different values of feed rate and depth of cut. It is observed that temperature linearly increases with cutting speed for any specified value of feed rate and depth of cut. This is due to the fact that with increased cutting speed, friction increases, which in turn increases the temperature in the cutting zone. The influence of depth of cut on temperature is quite evident from this figure. Accordingly, for a given feed rate and cutting speed, adopting smaller values of depth of cut could reduce the temperature. It is quite obvious that if both feed rate and depth of cut simultaneously increase, the shear plane area increases and hence plastic strain and friction increase; this leading to higher temperature. It can be also seen from Figure 7 that the temperature rise is more sensitive to cutting speed variation when the depth of cut is fixed at larger values. A similar situation exists when the feed rate is fixed at low values. Therefore, it can be concluded that minimum temperature can be achieved by adopting lower values of depth of cut and cutting speed with medium value of feed rate.

Figure $8(a-b)$ illustrates the microstructure of AISI D2 steel having martensitic structure with carbides) and microstructure of slightly annealed AISI D2 steel consisting of ferrite (iron) and alloy carbides. It is observed that there is a slight deformation of the grains below the surface. In this case the interaction between tool and work material resulted in small microstructural changes in the D2 steel layer, which was more easily deformed above annealing temperature (approx. $700^{\circ} \mathrm{C}$ ) owing to heat generated at the tool/chip interface caused by plastic deformation and friction ${ }^{1}$.

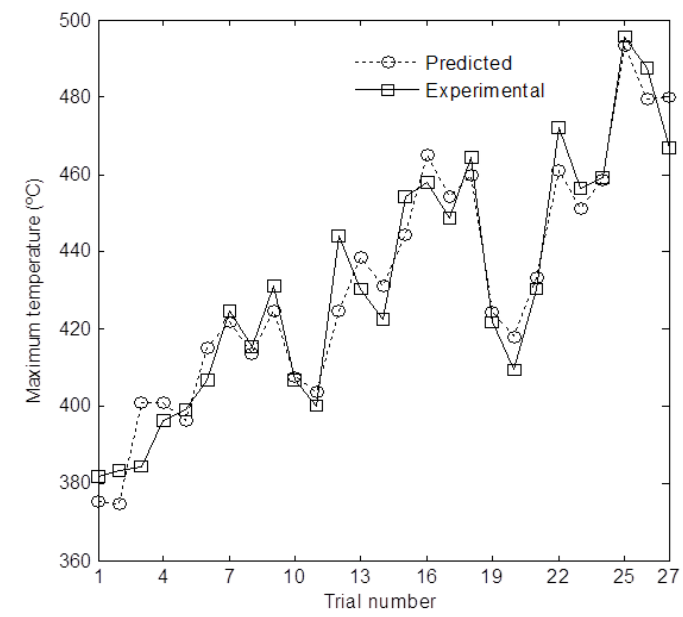

Figure 4. Comparison between experimental and predicted values for maximum temperature

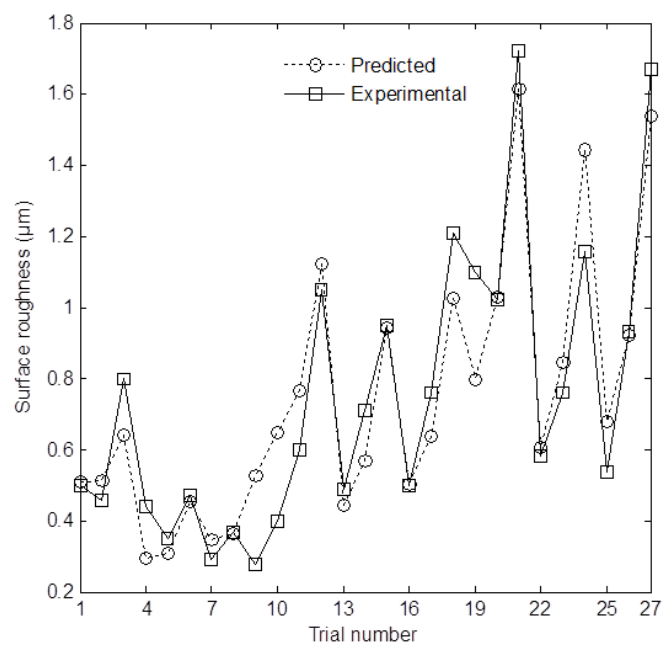

Figure 5. Comparison between experimental and predicted values for surface roughness

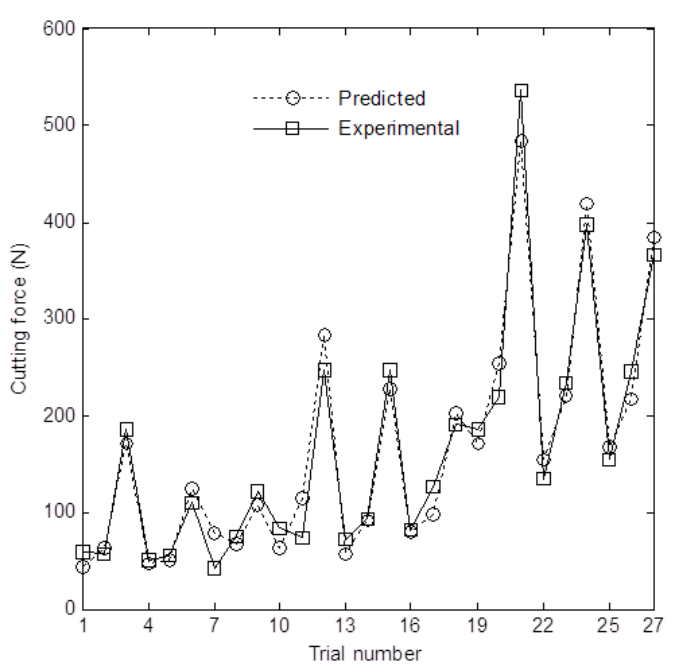

Figure 6. Comparison between experimental and predicted values for cutting force 
Table 5: Comparison of measured and predicted values of machinability characteristics for validation data

\begin{tabular}{|c|c|c|c|c|c|c|c|c|c|}
\hline \multirow{3}{*}{ Trial No. } & \multirow{2}{*}{\multicolumn{3}{|c|}{ Actual setting values of parameters }} & \multicolumn{6}{|c|}{ Responses } \\
\hline & & & & \multicolumn{3}{|c|}{ Experimental } & \multicolumn{3}{|c|}{ Predicted } \\
\hline & $v(\mathrm{~m} / \mathrm{min})$ & $f(\mathrm{~mm} / \mathrm{rot})$ & $d(\mathrm{~mm})$ & $T_{\max }\left({ }^{\circ} \mathrm{C}\right)$ & $R_{a}(\mu \mathrm{m})$ & $F_{c}(\mathbf{N})$ & $T_{\max }\left({ }^{\circ} \mathrm{C}\right)$ & $R_{a}(\mu \mathrm{m})$ & $F_{c}(\mathbf{N})$ \\
\hline 1 & 115 & 0.3 & 7 & 401.9 & 0.63 & 150.43 & 417.31 & 0.69 & 134.85 \\
\hline 2 & 105 & 0.3 & 5 & 410.5 & 0.67 & 112.19 & 398.13 & 0.55 & 104.26 \\
\hline 3 & 95 & 0.3 & 6 & 374.0 & 0.81 & 110.48 & 400.84 & 0.70 & 130.58 \\
\hline 4 & 100 & 0.2 & 4 & 385.9 & 0.34 & 61.43 & 379.85 & 0.44 & 58.44 \\
\hline 5 & 150 & 0.25 & 5 & 415.0 & 0.44 & 69.98 & 413.42 & 0.40 & 65.05 \\
\hline
\end{tabular}
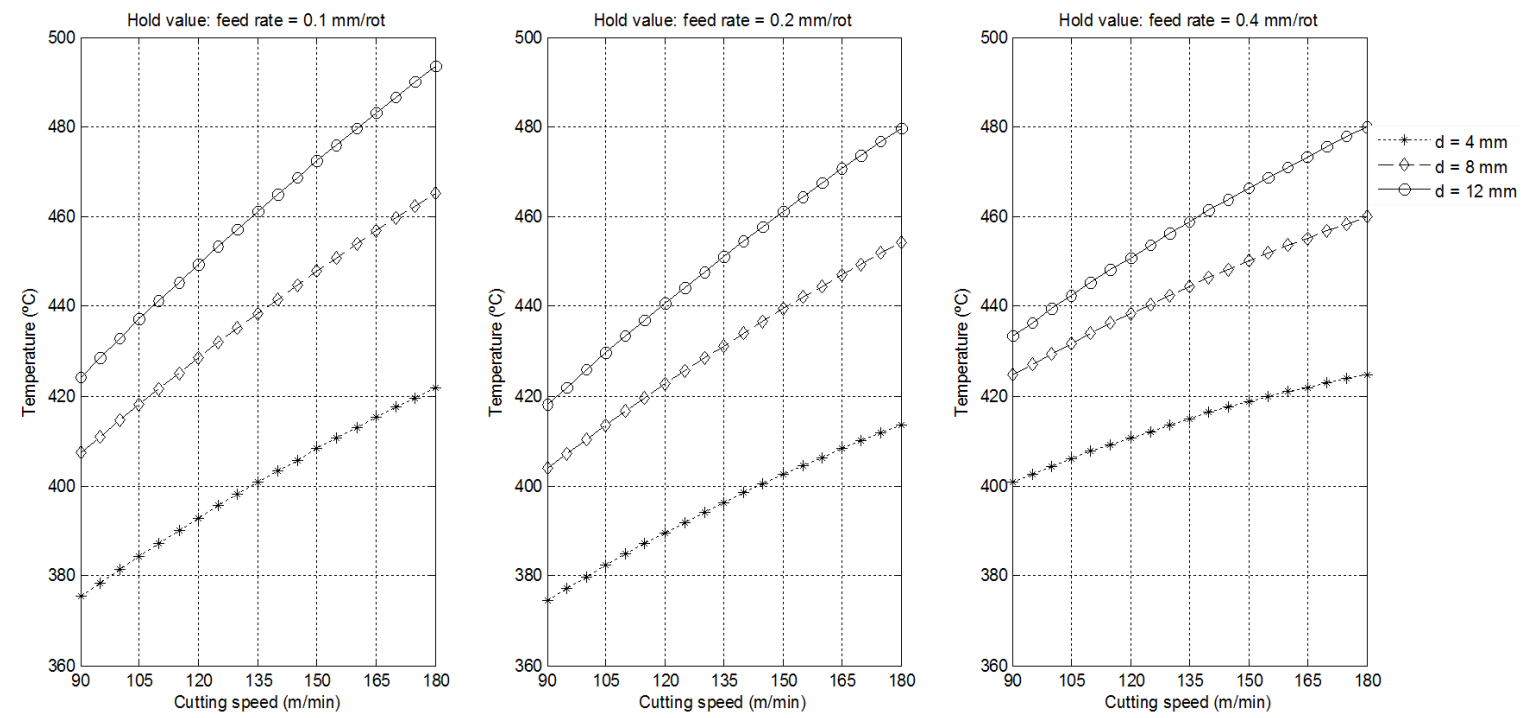

Figure 7. Effect of process parameters on maximum milling temperature

\subsection{Analysis of surface roughness}

The behavior of surface roughness with the process parameters during milling AISI D2 steel is given in Figure 9. The surface roughness is nonlinearly related to cutting speed variations for any values of feed rate and depth of cut. For specified values of feed rate and depth of cut, minimum surface roughness occurs at a medium cutting speed value of approximately $140 \mathrm{~m} / \mathrm{min}$. Moreover, surface roughness increases with depth of cut for all fixed values of cutting speed and feed rate. As can be seen from Figure 9, for a specified value of cutting speed and depth of cut, surface roughness increases with feed rate. In general, with increased feed rate, the contact area between the cutting tool and workpiece increases, causing higher thrust force and vibration and hence increased surface roughness. Additionally, with increased depth of cut the surface roughness also increases because more heat is generated at the cutting zone due to higher thrust force. It is also observed that with the elevation of feed rate the increase in surface roughness is not substantial when the depth of cut is fixed at the lowest value $(4 \mathrm{~mm})$ compared with medium $(8 \mathrm{~mm})$ and high $(12 \mathrm{~mm})$ depths of cut. Thus, surface roughness exhibits higher sensitivity to feed rate variations in the range from 0.2 to $0.4 \mathrm{~mm} /$ rot. Therefore, good surface finish can be obtained by adopting low values of both feed rate and depth of cut while operating with medium value of cutting speed. It is well known that with increased cutting speed, thermal softening of the work piece takes place and as a result the built-up edge formed on the milling cutter will be removed.

\subsection{Analysis of cutting force}

Figure 10 depicts the effect of process parameters on cutting force. It is clearly seen that the variation of cutting force with cutting speed is minimal when the feed rate is fixed at low and medium values. On the other hand, for higher values of feed rate, an increase in cutting speed greatly reduces the cutting force for all values of depth of cut. Besides, it is obvious that for fixed values of cutting speed and depth of cut, an increased feed rate results in increased cutting force values. At higher values of feed rates, the workpiece material presents more resistance to cutter in the cutting direction and hence friction increases, thus leading to increased cutting force. With a further increase in depth of cut, the material removal rate increases contributing to higher cutting force. It is also observed that the increase in cutting force is larger when the feed rate is increased from medium to the highest value. It can be concluded that a combination of low cutting speed, feed rate and depth of cut is essential to minimize the cutting force, as seen from Figure 10. 


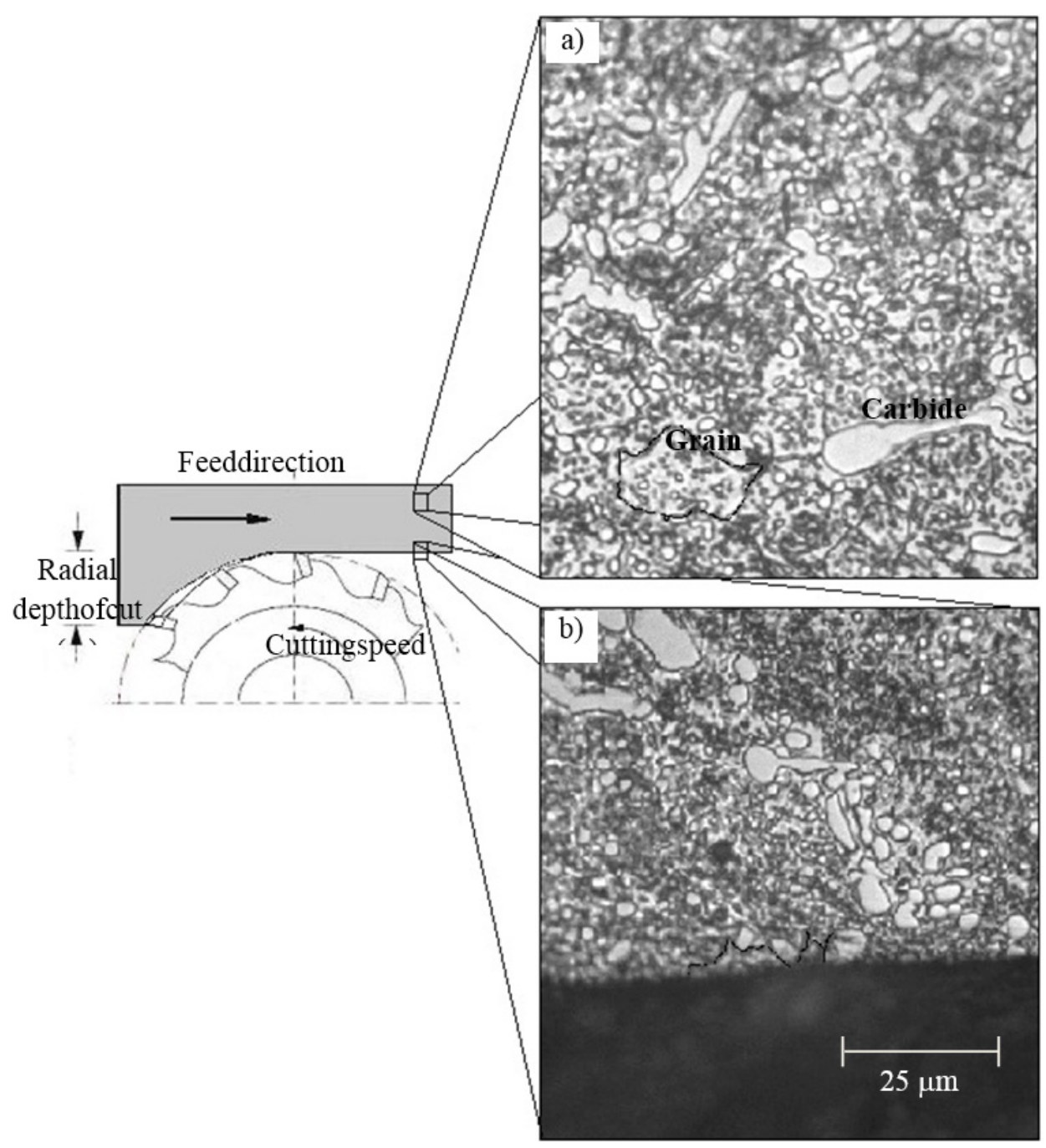

Figure 8. a) Microstructure of D2 steel having martensitic structure with carbides. b) Microstructure of slightly annealed D2 steel consisting of ferrite (iron) and alloy carbides
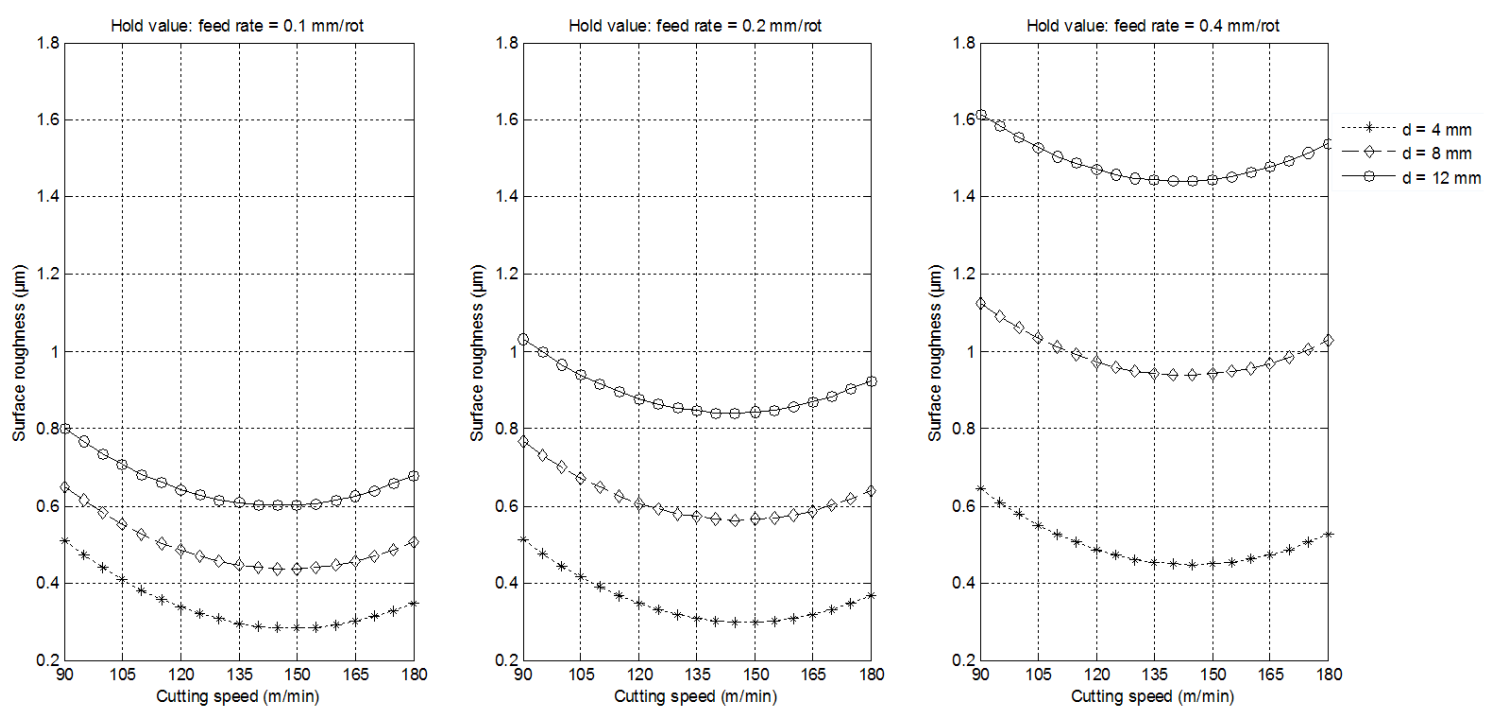

Figure 9. Effect of process parameters on work surface roughness 

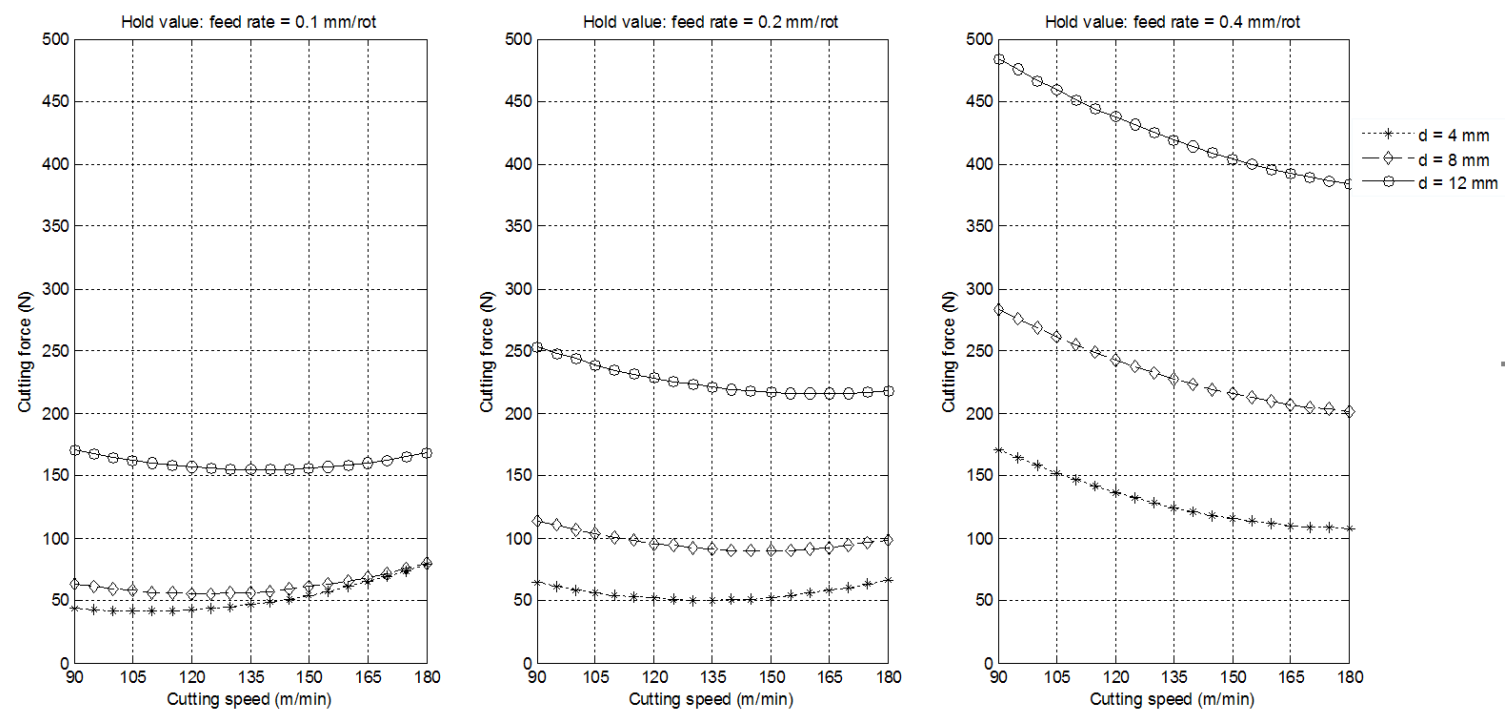

Figure 10. Effect of process parameters on cutting force

\section{Conclusions}

The influence of cutting speed, feed rate and radial depth of cut on various machinability characteristics such as maximum temperature $\left(T_{\max }\right)$, surface roughness $\left(R_{a}\right)$ and cutting force $\left(F_{c}\right)$ have been analyzed during milling of AISI D2 steel with TiAlN coated tungsten carbide insert using response surface methodology (RSM) based quadratic models. Based on the experimental results and subsequent analysis, the following conclusions are drawn:

- For specified values of feed rate and cutting speed, smaller depth of cut is essential to reduce the temperature.

- Minimum temperature can be achieved by adopting lower values of depth of cut and cutting speed with medium value of feed rate.

\section{References}

1. Trent E M, Wright PK. 2000 Metal cutting. 4th ed. Woburn, MA: Butterworth-Heinemann; 2000.

2. Saedon JB, Soo SL, Aspinwall DK, Barnacle A, Saad NH. Prediction and optimization of tool life in micromilling AISI D2 ( 62 HRC) hardened steel. Procedia Engineering. 2012;41:1674-1683. doi:10.1016/j.proeng.2012.07.367

3. Iyer R, Koshy P, Ng E. Helical milling: An enabling technology for hard machining precision holes in AISI D2 tool steel. International Journal of Machine Tools and Manufacture. 2007; 47(2): 205-210. doi:10.1016/j.ijmachtools.2006.04.006

4. Wang CY, Xie YX, Qin Z, Lin HS, Yuan YH, Wang QM. Wear and breakage of TiAlN- and TiSiN-coated carbide tools during high-speed milling of hardened steel. Wear. 2015;336-337: 29-42.DOI: 10.1016/j.wear.2015.04.018

5. Chengyong W, Xie Y, Zhenf L, Qin Z, Tang D, Song Y. Research on the chip formation mechanism during the highspeed milling of hardened steel. International Journal of Machine Tools and Manufacture. 2014;79:31-48. DOI: 10.1016/j. ijmachtools.2014.01.002
- Good surface finish can be obtained with a medium cutting speed of $140 \mathrm{~m} / \mathrm{min}$ for any given value of feed rate and depth of cut.

- The increase in surface roughness is not significant for lower depth of cut as compared to medium and high dept of cut values. The surface roughness exhibits higher sensitivity to feed rate variations in the range from 0.2 to $0.4 \mathrm{~mm} /$ rot.

- Better surface quality can be obtained by employing lower values of feed rate and depth of cut while operating at medium cutting speed.

- The increase in cutting force is large when the feed rate is increased from medium to high value. A combination of low cutting speed, feed rate and dept of cut is essential to minimize the cutting force.

6. Pu Z, Singh A. High speed ball nose end milling of hardened AISI A2 tool steel with PCBN and coated carbide tools. Journal of Manufacturing Processes. 2013;15(4):467-473. doi:10.1016/j. jmapro.2013.05.005

7. Wojciechowski S, Twardowski P. Tool life and process dynamics in high speed ball end milling of hardened steel. Procedia CIRP. 2012; 1: 289-294. doi:10.1016/j.procir.2012.04.052

8. Wojciechowski S, Twardowski P. The influence of tool wear on the vibrations during ball end milling of hardened steel. Procedia CIRP. 2014; 14: 587-592. doi:10.1016/j.procir.2014.03.108

9. de Aguiar MM, Diniz AE, Pederiva R. Correlating surface roughness, tool wear and tool vibration in the milling process of hardened steel using long slender tools. International Journal of Machine Tools and Manufacture. 2013; 68: 1-10. doi:10.1016/j.ijmachtools.2013.01.002

10. Liao YS, Lin HM. Mechanism of minimum quantity lubrication in high-speed milling of hardened steel. International Journal of Machine Tools and Manufacture. 2007;47(11):1660-1666. doi:10.1016/j.ijmachtools.2007.01.007

11. Liao YS, Lin HM, Chen YC. Feasibility study of the minimum quantity lubrication in high-speed end milling of 
NAK80 hardened steel by coated carbide tool. International Journal of Machine Tools and Manufacture. 2007; 47(11): 1667-1676. doi:10.1016/j.ijmachtools.2007.01.005

12. Begic-Hajdarevic D, Ceki A, Kulenovic M. Experimental study on the high speed machining of hardened steel. Procedia Engineering. 2014; 69: 291-295. doi:10.1016/j.proeng.2014.02.234

13. Durakbasa M, Akdogan A, Vanli AS, Bulutsuz AG. Optimization of end milling parameters and determination of the effects of edge profile for high surface quality of AISI H13steel by using precise and fast measurements. Measurement. 2015; 68:92-99. DOI: 10.1016/j.measurement.2015.02.042

14. Beake BD, Li Ning, Gey C, Veldhuis SC, Komarov A, Weaver A, et al. Wear performance of different PVD coatings during hard wet end milling of H13 tool steel. Surface and Coatings Technology. 2015:279:118-125. doi:10.1016/j.surfcoat.2015.08.038

15. Brandão LC, Coelho RT, Rodrigues AR. Experimental and theoretical study of workpiece temperature when end milling hardened steels using (TiAl)N-coated and PcBNtipped tools. Journal of Materials Processing Technology. 2008:199 (1-3): 234-244. doi:10.1016/j.jmatprotec.2007.07.049

16. Qinglong An, Wang C, Xu J, Liu P, Chen M. Experimental investigation on hard milling of high strength steel using PVDAlTiN coated cemented carbide tool. International Journal of Refractory Metals and Hard Materials. 2014;43:94-101. doi:10.1016/j.ijrmhm.2013.11.007
17. Lu L, Wang Q, Chen B, Ao Y, Yu D, Wang C, et al. Microstructure and cutting performance of CrTiAlN coating for high-speed dry milling. Transactions of Nonferrous Metals Society of China. 2014; 24(6): 1800-1806. doi:10.1016/S1003-6326(14)63256-8

18. Koshy P, Dewes RC, Aspinwall DK. High-speed end milling of hardened AISI D2 tool steel ( $\sim 58$ HRC). Journal of Materials Processing Technology. 2002;127(2):266-273.

19. American Society for Metals. Properties and Selection: Irons and Steels, and high-performance alloys. 9th ed. Ohio: Metals Park; 1998. (ASM Handbook, vol. 1)

20. Nurul Amin AK, Dolah SB, Mahmud MB, Lajis MA. Effects of workpiece preheating on surface roughness, chatter and tool performance during end milling of hardened steel D2. Journal of Materials Processing Technology. 2008;201(1-3):466-470. doi:10.1016/j.jmatprotec.2007.11.304

21. Kang MC, Kim KH, Shin SH, Jang SH, Park JH, Kim C. Effect of the minimum quantity lubrication in high-speed end-milling of AISI D2 cold-worked die steel (62 HRC) by coated carbide tools. Surface and Coatings Technology. 2008;202(22-23):56215624. doi:10.1016/j.surfcoat.2008.06.129

22. Okada M, Hosokawa A, Tanaka R, Ueda T. Cutting performance of PVD-coated carbide and CBN tools in hard milling. International Journal of Machine Tools and Manufacture. 2011;51(2):127-132.

23. Montgomery DC. Design and Analysis of Experiments. New York: John Wiley; 2004. 